Einwirkung des Chloroforms auf die Sinnplanze. 57

Regen verschieden ausfallen; dennoch bleibı das Verhältniss des Zuckers zur Holzsubstanz constant.

1000 Theile des ungeschälten Rohrs geben 1,86 Theile in Wasser unlöslicher Asche; die löslichen Salze des ganzen Rohrs betragen 1,4 Theile auf 1000 Theile.

Durch geeignete Schälmaschinen glaubt der Verfasser in der Zuckerfabrication bedeutende Verbesserungen machen zu können, indem man die Rinde entfernen könnte. Die geringere Anstrengung der Maschine zur Zermalmung, und eine zerkleinertere Masse würde den Verlust an Zucker, welcher mil der Rinde entfernt wird, gewiss sehr uberwiegen. (Annal. de Chim. et de Phys. - Pharm. Centrbl. 1849. No. 24.)

B.

\title{
Einwirkung des Chloroforms auf die Sinnpflanze (Mimosa pudica).
}

Nach Marcet bemerkt man, wenn man einen oder zwei Tropfen reines Chloroform auf die Spitze des allgemeinen Blattstiels der Sinnpflanze bringt, dass derselbe unmittelbar darauf einschlält; einen Augenblick nachher schliessen sich die Blälter, und zwar so, dass die am Ende eines jeden $\mathrm{Zv}$ eiges befindlichen den Anfang machen. Nach Verlauf von ein bis zwei Minuten, je nachdem die Pflanze mehr oder minder kräftig ist, schlafen auch die unler den chloroformirten Blättern auf demselben Stengel zunächst sitzenden Blätter, ein Blatt nach dem andern, ein und ihre Blättchen legen sich zusammen; letzteres geschieht aber weniger vollständig, als bei den unmillelbar mit dem Chloroform in Berührung gebrachten Blättern. Nach längerer Zeit, je nach der Kräfigkeit der Pflanze, beginnen die Blätter sich allmälig wieder zu öffnen; bei der Berührung zeigt sich, dass sie gegen dieselbe fast unempfindlich sind. In dieser Erstarrung bleiben die Blätler einige Zeit und erlangen ihre frühere Sensibilät erst nach mehreren Stunden wieder.

Eine ähnliche Erscheinung findet statt, wenn man, anstatt das Cbloroform auf die Basis des Blattstiels zu bringen, die Blättchen, welche am Ende jedes Zweiges sitzen, mit demselben benetzt. Die Blätter dieses Zweiges fangen unmittelbar darauf an, paarweise einzuschlafen; dasselbe geschieht dann mit dem Blattstiele und zuletzt auch mit den Blättern der anderen $Z$ weige desselben Blattstiels. Nach 2 bis 3 Minuten folgte das zunächst sitzende Blatt und, wenn die Pflanze kräftig ist, auch die 
meisten der an demselben Stengel sitzenden Blätter dem Beispiele der anderen. Wenn sich nach einiger Zeit die Bläller öffnen, so gerathen sie in denselben Zustand der Gefühllosigkeit, wie oben erwähnt wurde.

Experimente ähnlicher Art über die Empfindlichkeit der Sinnpflanze mit rectificirtem Aether angestellt, gaben Marcet ähnliche Resultate; es zeigte sich aber darin ein Unterschied, dass, während ein Tropfen Chloroform auf den allgemeinen Blattstiel eines am Ende des Zweiges der Sinnpllanze befindlichen Blattes gebracht, hinreichte, um die meisten der anderen daruntersitzenden Blätter desselben Zweiges zu schliessen, der Aether gewöhnlich nur auf das Blatt wirkte, mit welchem er in Berührung kam. Die benachbarten Blälter scheinen nicht afficirt zu werden. Es muss jedoch bemerkt werden, dass diese Versuche mit dem Aether nach den anderen und in einer Jahreszeit angestellt wurden, in welcher die Sensibilität sich zu mindern begann. (Journ. f. prakt. Chem. Bd.46. p. 417.)

E. St.

\section{Steinkohlentheer.}

Nachdem Charles Blachford Mansfield darauf hingewiesen, dass der Steinkohlentheer aus einer grossen Anzabl öliger Bestaniltheile zusammengesetzt ist, die neutraler, basischer oder saurer Natur sind, hebt er hervor, dass von jeder dieser drei Classen ein Repräsentant eine Hauptrolle bei der Entwickelung der interessantesten Thatsachen in der neueren Chemie gespielt habe. Naphthalin, Anil, Phenol haben durch ihre Substitutionsproducte und durch die Beziehungen, welche sie zu anderen Körpern zeigen, mit am meisten zur Ausbreitung der Radicaltheorie beigetragen. Der Umstand nur, dass wir mit den flüssigen neutralen Oelen des Steinkohlentheers nur wenig bekannt sind, veranlasste Mansfield zu einer Unlersuchung, die hier kurz mitgetheilt werden soll.

Die bei der Destillation des Steinkohlentheers zuerst ubergehenden Stoffe sind Ammoniak und wahrscheinlich permanente Gase; bei steigender Temperatur gebt Wasser, beladen mit verschiedenen Ammoniakverbindungen, über, begleitel von einem stinkenden gelben, oder braunen Oel, das auf der Oberfläche des Wassers schwimmt. Es nimmt allmälig an Menge und Schwere zu; nach einiger Zeit destillirt ein Oel, das in Wasser untersinkt. Es wird dann die Vorlage gewechselt, und man erhält so das leichte Oel und das schwere Oel getrennt von einander. Enthält 